\title{
AUTISMO: INCLUSÃO DA CRIANÇA AUTISTA NA SALA DE AULA
}

\author{
Artemes Cristina Pires Lamar ${ }^{1}$ \\ Robson Canteiro Valenzuela ${ }^{2}$ \\ Raquel dos Santos Nascimento ${ }^{3}$
}

RESUMO: Este artigo se propõe a discutir as deficiências no processo de ensino/aprendizagem escolar do aluno autista e sugerir algumas orientações para que o professor regente ou auxiliar possa trabalhar com esta criança especial. A partir do pressuposto de que o professor pouco ou nada conhece sobre o Autismo ou Transtorno do Espectro Autista e o impacto causado por esta anomalia no processo do ensino aprendizagem em suas diversas características.

Palavras-chave: Autismo. Ensino. Aprendizagem. Aluno/ Professor.

ABSTRACT: This article aims to discuss the difficulties in the teaching/learning process of the autistic student and suggest some guidance so that the teacher regent or auxiliary can work with this special child. Based on the assumption that the teacher knows little or nothing about Autism or autism spectrum disorder and the impact caused by this anomaly in teaching learning in its various characteristics.

Keywords: Autism. Teaching. Apprenticeship. Student/ Teacher.

\section{INTRODUÇÃO}

Segundo pesquisas foi somente a partir da década de 6o que começou a falar sobre crianças especiais, até então essas crianças especiais eram isoladas por suas famílias e muitas delas nunca adentraram um estabelecimento escolar. Aqueles que tinham posse contratava uma professora particular, porém aqueles que não tinha condições não estudava. As dificuldades e os transtornos de aprendizagem se apresentam sempre na infância e teve um forte impacto sobre a vida dessa criança,

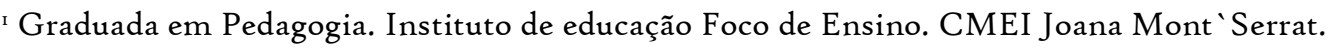
Cuiabá.MT.E-mail: artemes.cristina@gmail.com.

${ }^{2}$ Especialista em Artes cênicas- Universidade Federal da Grande Dourados Pedagogia_Faculdade Magsul Especialista em Artes Visuais Faveni CMEI Joana Mont 'Serrat. Cuiabá. MT. E-mail: robsoncanteiro@outlook.com.

3 Graduada em Pedagogia. Faculdades integradas de Ariquemes (FIAR). Rondônia RO. E-mail: nascimentoraquel37@gmail.com.
} 
sua família e sobre o seu entorno. E dentre esses transtornos destacamos o Autismo.

A expressão Autismo foi utilizada primeiramente por Bleuer, em I9II. E anos mais tarde (1943) Leo Kanner designou os comportamentos associados ao de Bleuer como Distúrbio Autístico do Contato Afetivo e, no ano seguinte Hanns Asperger, usou a expressão Psicopatia Autística para designar o Autismo. Num artigo intitulado "Autistic Disturbance off Afective Contact” Kanner descreveu: (...) desde 1938 chega a nossa atenção um número de criança cuja condição difere tão marcada e unicamente de qualquer coisa referida até hoje, que cada caso merece, eu espero que eventualmente receba-uma considera ao detalhado das suas peculiaridades fascinantes.

Nas décadas seguintes o Autismo se fortaleceu como uma entidade diagnostica sendo estudado e analisados por muitos pesquisadores interessados em descobrir esse estranho comportamento. Muito se pesquisou sobre esse transtorno, porém os dados da pesquisa na área de autismo da última década apontam para inúmeras descobertas em direção a causa biológica do autismo (ou as possíveis causas). Infelizmente até a presente data não existe um tratamento médico que tenha demonstrado eficacia no sentido de melhorar os sintomas primordiais (prejuízos nas áreas de interação social e comunicação).

Mas afinal o que é o Autismo? E um transtorno do neurodesenvolvimento, que conforme pesquisa afeta 5 a cada afetados são do sexo masculino. E infelizmente segundo estudos mais recentes houve aumento na quantidade de crianças afetadas pelo distúrbio chegando a 6o em cada 10.000 crianças, mostrando um aumento assombroso no número de casos. Como Leo Kanner Efetivou a sua pesquisa? Observando que um determinado grupo de crianças apresentava isolamento social aliterações da fala e necessidade extrema de manutenção da rotina. A esta lista de sintomas Kanner denominou autismo.

As causas do autismo ainda são desconhecidas, mas a pesquisa na área é cada vez mais intensa. Provavelmente, ha uma combinação de fatores que levam ao autismo. Sabe-se que a genética e agentes externos desempenham um papel behave 
nas causas do transtorno Conforme a Associação Médica Americana, as hipóteses de uma criança desenvolver autismo devido à herança genética são de 50\% de qualquer maneira muitos genes parecem estar envolvidos nas causas do autismo. Alguns tornam as crianças mais suscetíveis ao transtorno. Outros afetam a desenvolvimento do cérebro e a comunicação entre os neurônios. Outros ainda determinam a gravidade dos sintomas.

Com o passar dos anos foi se percebendo que o autismo se fortaleceu como uma entidade diagnóstica sendo estudado por muitos pesquisadores. E nessas pesquisas o conceito de autismo foi se ampliando, admitindo-se hoje que existem diferentes graus de autismo. Conforme dados levantados segundo a descrição inicial de Kanner, se considerava autista somente indivíduo com grave comprometimento para a vida diária. Portanto, fundamental entendermos que o autismo hoje é considerado uma síndrome comportamental em que encontramos um leque de gravidade para o conjunto dos sintomas.

O autismo é um transtorno de desenvolvimento que geralmente aparece nos trés 1290 primeiros anos. Na literatura médica estão descritas inúmeras doenças e alterações genéticas que sabidamente se correlacionam com a presença de sintomas de autismo. Dentre elas podemos citar a síndrome de rubéola congênita, anomalias de formação do cerebelo, esclerose tuberosa, síndrome de Rett, (meninas) síndrome de West, síndrome de Asperger e síndrome do sexo frágil. A criança autista pode apresentar aparência totalmente normal, e também um perfil irregular de desenvolvimento.

Os principais sintomas do autismo, decorrentes de problemas físicos no cérebro, são: os distúrbios no ritmo de aparecimentos de habilidades físicas, sociais e linguísticas; a reações anormais as sensações. As funções ou áreas mais afetadas são: visão, audição, tato, dor, equilíbrio, olfato, gustação e maneira de manter o corpo; a fala e a linguagem ausentes ou atrasadas, certas áreas especificam do pensar, presentes ou não, ritmo imaturo da fala, restrita compreensão de ideias. 


\section{O papel do professor}

Após leitura e pesquisas, observamos que alguns passos devem ser tornados no âmbito da intervenção precoce em Autistas. Geralmente é o professor o primeiro a identificar que a criança esta com alguma dificuldade, mas os pais e demais membros da família devem ficar atentos ao desenvolvimento e ao comportamento da cri anga promovendo sua melhor aprendizagem e encaminhando-a a um clínico. Esse dará continuidade ao diagnóstico desta cri anga, o que envolvera todos os profissionais necessários e a família do aluno, para este poder viver em sociedade como uma pessoa normal e sendo compreendido em suas diferenças.

O papel da escola é fazer o reconhecido no nível da educação, na elaboração de estratégias para que estes alunos com autismo consigam desenvolver capacidades para se integrar e interagir com as outras crianças ditas "normais". Já a família tem também um papel importante, pois é a responsável por dar atenção, os cuidados, amor e devera zelar por toda uma vida. E necessário dispensar algumas horas para que as crianças possam se sentir queridas e mostrar o que aprenderam. 'Até agora, os sistemas de ensino têm lidado com a questão através de medidas faGilitadoras, como cuidadores, professoras de reforço e salas de acelera ao, que não resolvem, muito menos atendem o desafio da inclusão. Pois, qualificar uma escola para receber todas as cri anças implica medidas de outra natureza, que visam reestruturar o ensino e suas praticas usuais e excludentes. $\mathrm{Na}$ inclusão, não é a criança que se adapta a escola, mas a escola que para recebê-la deve se transformar ${ }^{\circ}$, aponta.

Escola deve conhecer as características da criança e prover as acomodações físicas e curriculares necessárias; treinar os profissionais continuamentebuscade novas informações; buscar consultores para avaliar precisamente as crianças preparando programas para atender a diferentes perfis visto que os autistas podem possuir diferentes estilos e potencialidades; ter professores cientes que inclusive a avaliação da aprendizagem deve ser adaptada; educadores conscientes que para o autismo, conhecimento e habilidades possuem definições diferentes; analisar o ambiente e evitar situações que tenham impacto sobre os alunos, alterar o ambiente 
se for possível; a escola deverá prover todo o suporte físico e académico para garantir a aprendizagem dos alunos incluídos; atividade física regular é indispensável para o trabalho motor; a inclusão não pode ser feita sem a presença de um facilitador e a tutoria deve ser individual; um tutor por aluno; a inclusão não elimina os apoios terapêuticos; necessidade de desenvolver um programa de educação paralelo à inclusão e nas classes inclusivas o aluno deve participar das atividades que ele tenha chance de sucesso, especialmente das atividades socializadoras. A escola deverá demonstrar sensibilidade as necessidades do indivíduo e habilidade para planejar com a família o que deve ser feito ou continuado em casa.

Segundo a Coordenadora da ONG Autismo e Realidade Joana Porto lese muitas vezes as equipes gestoras não estão preparadas para desenvolver um plano pedagógico com as crianças as autistas, e com isso elas buscam acompanhamento de um orientador terapêutico o que, na visão da coordenadora, é um erro. "Não se deve promover a substituição segundo ela. Quando se entende que um profissional desse é necessário na escola, o trabalho deve ser complementar. sem que isso diminua a responsabilidade do professor", Per isso, mais do que a aprendizagem em si é preciso se ater a qualidade de ensino oferecida. 'E necessário um piano de ensino que respeite a capacidade de cada aluno e que proponha atividades diversificadas para todos e considere o conhecimento que cada aluno traz para a escola". os educadores devem desenvolver um programa de educação individualizado para focalizar nos problemas específicos da criança. Isto inclui terapia de fala e do idioma, e também habilidades sociais e treinamento de habilidades cotidianas. Eles devem elaborar estratégias para que essas crianças consigam desenvolver capacidades de interação com outras crianças. Inclusive algumas crianças são incapazes de se concentrar, mesmo por poucos segundos. Para superar esta dificuldade, é necessário planejar situações de ensino estruturado, dividindo em pequenos passos e metas o que elas devem aprender.

Abaixo descreveremos algumas características onde o professor deve se manter atento. O professor deve estar atento ao fixação ocular da criança com autismo, 
porque as crianças portadoras do Espectro Autista têm dificuldade em centralizar sua visão ou mesmo focar a sua atengâo em determinados objetos, ou mesmo de olhar no rosto dos próprios pais. A criança autista tem severas dificuldades em perceber o triangulo existente entre olhos, nariz e boca como também se sente insegura ao movimentar o seu olhar sem saber bem como lo fixa.

Portanto, ao interagir com esse aluno é bom direcionar esse trígono e fixar bem os olhos nela enquanto está se interagindo. O professor tem que estar atento ao se dirigir a um aluno autista. Sempre que conversar, abaixe e olhe bem nos olhos dele. Ao mostrar qualquer objeto coloque sempre no campo centro visual. 1sso fara com que ele se sinta estimulado a perceber outras áreas cerebrais. Outras situações que temos que estar atentos é quanto a hipersensibilidade que eles sentem na pele, na audição, na visão Levando-os as crises de choro levando às vezes até a automutilação.

O que se percebe é que eles não conseguem assimilar ou mesmo se organizar, ou harmonizar essas sensações fazendo com que elas se tornem menos doloridas. $O$ professor, ao iniciar o processo de inclusão de uma criança com necessidades educacionais especiais associadas ao autismo infantil, pode sentir-se incapaz de interagir com essa criança. A sensação é de que a criança apenas se recusa a interagir com o professor e a aprender qualquer coisa proposta por ele. lsso acontece porque algumas habilidades necessárias para o aprendizado e presentes mesmo em criança com deficiência mental, considerada pela maioria dos professores comuns a todas as crianças, não são encontradas nas crianças autistas (SANTOS, 2013)

\section{3- Fatores lmportantes.}

Outro ponto importante é o entendimento de que serão descritas as peculiaridades cognitivas (ou o estilo cognitivo) de portadores de autismo e não os defeitos cognitivos. O fato de existirem diferenças na maneira de processar os estímulos e de vivenciar o mundo não quer dizer que os dos não autistas é o certo e que o dos autistas é o errado.

I. Segundo a Wikipédia desde 2oro, a taxa de autismo é estimada em cerca de I- 
2 a cada r.ooo pessoas em todo o mundo, ocorrendo 4 - 5 vezes mais em meninos do que meninas. Cerca de $1,5 \%$ das crianças nos Estados Unidos (uma em cada 68) são diagnosticadas com ASD, a partir de 2014, houve um aumento de 30\%, uma cada 88 , em 2012. A taxa de autismo em adultos de 18 anos ou mais no Reino Unido é de I.I\% o número de pessoas diagnosticadas vem aumentando drasticamente desde a década de 1980. Em parte devido a mudanças na prática do diagnóstico e incentivos financeiros subsidiados pelo governo para realizar diagnósticos; a questão se as taxas reais têm aumentado realmente, ainda não é conclusivo

2. Outro ponto importante abordado no quadro acima é o fato de existir uma tendência a um pensamento visual nos autistas. Templo Grandin (1996), uma autista famosa e hoje já uma senhora, relata com grande precisão o fato de seus pensamentos serem totalmente visual. Templo refere.que as palavras que Ié e escuta parecem que instantaneamente se transformam em imagens coloridas como se vê em um filme. Ela relata que se surpreendeu quando descobriu, já mais velha, que as outras pessoas não pensavam visualmente como ela e que para a maior parte das pessoas as habilidades linguísticas eram maiores que as viso-espaciais. Portanto, o nível intelectual não é o que determina o autismo e sim as dificuldades na interação social, comunicação e o repertório restrito de hábitos e interesses. A proposta de educação inclusiva (Tratado da Guatemala, 199ı; Declaração de Salamanca, 1994) declara que todos os alunos devem ter a possibilidade de integrar-se ao ensino regular, mesmo aqueles com deficiências sensoriais, mentais, cognitivas ou apresentarem transtornos severos de comportamento, preferencialmente sem defasagem idade-série. A escola, segundo essa proposta, devera adaptar-se para atender as necessidades destes alunos inseridos em classes regulares. Portanto, a educação inclusiva devera ser posta em prática numa escola inclusiva que busque ações que favorecem a integração e a opgção por práticas heterogêneas. Em 1996 foi publicada a Lei de Diretrizes e Bases da Educação Nacional, que em seu artigo (59) preconiza que os sistemas de ensino devem assegurar aos alunos currículo, métodos, recursos e organização específicos para atender as suas necessidades. Em 2008, foi publicada a política Nacional de 
Educação Especial na Perspectiva da Educação Inclusiva, que preconiza o acesso, a participação e a aprendizagem dos alunos com deficiência, transtornos globais do desenvolvimento e altas habilidades, nas escolas regulares (BRASIL, 2008).

A escola deve conhecer as características da criança $e$ prover as acomodações físicas e curriculares necessárias; treinar os profissionais continuamente e busca de novas informações; buscar consultores para avaliar precisamente as crianças; preparar programas para atender a diferentes perfis visto que os autistas podem possuir diferentes estilos e potencialidades; ter professores cientes que inclusive a avaliação da aprendizagem deve ser adaptada; educadores conscientes que para o autismo, conhecimento e habilidades possuem definições diferentes; analisar o ambiente e evitar situações que tenham impacto sobre os alunos, alterar o ambiente se for possível.

E importante a continuidade do ensino para uma criança autista, para se tornar menos dependente, mesmo que isto envolva varias tentativas, e eta não consiga aprender. E preciso atender prontamente toda vez que a criança autista solicitar e tentar o dialogo, a interação.

Quando ocorrer de chamar uma criança autista e ela não atender, é necessária ir até ela, pegar sua mão e Leva-la para fazer o que foi solicitado. Toda vez que a criança conseguir realizar uma tarefa, ou falar uma palavra, ou enfim, mostrar progresso, é prudente reforçar com elogios. Quando se deseja que a criança olhe para o professor, segura-se delicadamente o rosto dela, direcionando-o para o rosto do professor. Pode-se falar com a criança, mesmo que seu olhar esteja distante, tendo como meta um desenvolvimento de uma relação baseada em controle, segurança, confiança e amor. Através da mediação do professor a criança poderá desenvolver uma adequação a aprendizagem e uma transformação as estruturas cognitivas da criança.

E importante a continuidade do ensino para uma criança autista, para se tornar menos dependente, mesmo que isto envolva varias tentativas, e ela não consiga aprender. E preciso atender prontamente toda vez que a criança autista solicitar e 
tentar o dialogo, a interação.

Quando ocorrer de chamar uma criança autista e ela não atender, é necessária ir até ela, pegar sua mão e Leva-la para fazer o que foi solicitado. Toda vez que a criança conseguir realizar uma tarefa, ou falar uma palavra, ou enfim, mostrar progresso, é prudente reforçar com elogios. Quando se deseja que a criança olhe para o professor, segura-se delicadamente o rosto dela, direcionando-o para o rosto do professor. Pode-se falar com a criança, mesmo que seu olhar esteja distante, tendo como meta um desenvolvimento de uma relação baseada em controle, segurança, confiança e amor. Através da mediação do professor a criança poderá desenvolver uma adequação a aprendizagem e uma transformação as estruturas cognitivas da criança.

O diagnóstico é apenas o primeiro desafio que o Brasil precisa enfrentar. Em seguida, vem o mais complicado, o tratamento. Ele tem de ser individualizado e envolve uma série de profissionais. Realizar um trabalho voltado para as dificuldades que envolvem o tema já justificaria a abordagem do mesmo. Trata-se de um levantamento bibliográfico acerca do tema seguido de alguma observação pautadas na experiência da autora com esse público. Faz- se necessário entender o processo de desenvolvimento e aprendizagem e, para isso, utilizaremos como referência a teoria do desenvolvimento cognitivo de Piaget, que traduz diferentes formas de organização mental e diferentes estruturas cognitivas, que servira como base para realizar um piano de ensino apropriado para cada criança autista. Este trabalho pretende: abordar o conceito, características e critérios de diagnóstico do autista; demonstrar a possibilidade de o autista poder se relacionar com a sociedade e potencial para aprender.

Quanto as adaptes de categoria de atividade é interessante relatar que o aprendizado, a motivação e o tempo de atenção melhoram muito quando o professor consegue misturar ao conteúdo escolar fato ou dados que tenham relâmpago.

Com isto, deve o professor e os demais educadores da escola tentem entender as 
questões de comportamento da criança portadora de autismo considerando a sua visão de mundo.

Não quer dizer que a escola tem que ceder as birras e aos gritos, mas entendendo o porquê fica mais fácil negociar, argumentar, antecipar, usar os recursos visuais e explicar o que esta acontecendo para a criança.

E de suma importância atividades de desenvolvimento para o pensamento Iérico, capacitar à autonomia intelectual e tenham prazer na busca pelo novo e atingir pensamentos inovadores. Utilizar como recursos a arte em um ambiente aberto, pincéis, diversas cores, telas, chão, paredes, espaços grandes em geral para tornar ainda mais prazeroso a prática, tendo melhor intervenção e visualizando a interação social. Jogos adequados, que contribuem de forma positiva, propiciando a vivência em equipe, a criatividade, concentração e atenção. $O$ incentivando, permitimos a conduta de outra criança de se aproximar e dar opinião, capacitando e dando a imaginação de descobertas.

Muitas têm grande potencial. Algumas podem até ter um pouco mais de dificuldades, não vão entender assuntos tão complexos, por conta da abstração. Mas, de forma geral, ela aprende e pode desenvolver uma vida normal. Vemos muitos alunos com dom para desenho, Matemática e Informática. As crianças autistas aprendem sim e nos proporcionam grandes alegrias!

\section{CONSIDERAÇÕES FINAIS}

Para finalizar, é importante que se fale da dificuldade de atenção encontrada nos alunos com autismo. Tal quadro varia, mais uma vez, conforme o grau do autismo e a faixa etária da criança. Esta queixa, porém, é extremante frequente sendo narrada a dificuldade para manter a atenção em atividade como "rodinha" ou leitura de estória (para os mais novos) e para prestar atenção nas aulas (para os mais velhos).

Concluindo, é fundamental que fique claro que quando se fala em educação para autismo deve se ter em mente que isto não se refere somente a aprendizado acadêmico e sim a um aprendizado mais global, que deve incluir habilidade social, 
linguagem, comunicação, comportamentos adaptativos e redução de comportamentos problemáticos. Este processo de educação em portadores de autismo deve envolver as famílias, professores, profissionais extra- escola envolvidos no caso, além dos próprios portadores de Autismo.

\section{REFERENCIAS}

1- Gikovate, C; Mousinho, R. Espectro Autistico e suas implicáveis educacionais. Rio de Janeiro: Revista SINPRO Ano 5, n.o 6, 2004: 26-33.

2- Gikovate, C - www.carlagikovate.com.or - site com orientação de autismo.

3- Nilsson, I - Introdução à educação especial para pessoas com transtorno do espectro Autistico e dificuldades semelhantes de aprendizado. Temas de desenvolvimento I2 (68): 5-45 maio-jun 2003.

4- Petters, T. Autismo: entendimento teórico e intervenção educacional. Cultura Médica, Rio de Janeiro. 